\title{
ASPECTOS ESTRATIGRÁFICOS E ANÁLISE DE MINERAIS PESADOS DAS FORMAÇÕES IPIXUNA, BARREIRAS E PÓS-BARREIRAS, ENTRE AS CIDADES DE JACUNDÁ E GOIANÉSIA DO PARÁ, SUB-BACIA DE MOCAJUBA, SUDESTE DO ESTADO DO PARÁ
}

\author{
STRATIGRAPHIC ASPECTS AND HEAVY MINERALS ANALYSIS OF THE IPIXUNA, BARREIRAS \\ AND POST-BARREIRAS FORMATIONS, BETWEEN THE CITIES OF JACUNDÁ AND GOIANÉSIA \\ DO PARÁ, MOCAJUBA SUB-BASIN, MARAJÓ BASIN, SOUTHEAST OF PARÁ STATE
}

\section{Meyre Jéssica JAMES¹, Antônio Emídio de Araújo SANTOS JÚNIOR ${ }^{1}$, Jeferson Sena da COSTA $^{2}$}

${ }^{1}$ Universidade Federal do Sul e Sudeste do Pará (UNIFESSPA). Faculdade de Geologia, Instituto de Geociências e Engenharias. Marabá-PA, Nova Marabá. Emails: meyrejames@gmail.com; emidiosantos@unifesspa.edu.br

${ }^{2}$ Universidade Federal do Pará (UFPA). Guamá Belém-PA. Email: jeferson.jscosta03@ gmail.com

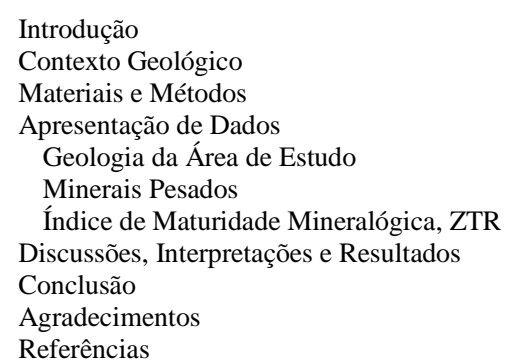

RESUMO - Os depósitos sedimentares expostos ao longo da rodovia BR-150, entre as cidades de Jacundá e Goianésia do Pará, pertencem ao contexto da borda sul da Sub-Bacia de Mocajuba, Bacia do Marajó, situada na Margem Equatorial Brasileira (MEQ). Utilizando-se de forma integrada critérios faciológicos/litoestratigráficos, dados de campo e minerais pesados, as rochas da área de estudo foram correlacionadas às formações Ipixuna, Barreiras e Pós-Barreiras/Argila Belterra. Estudo de minerais pesados nestes depósitos permitiram identificar a seguinte assembleia mineralógica: zircão, turmalina, rutilo, estaurolita e cianita, com índice ZTR de alta maturidade em todas as unidades estratigráficas. Os minerais pesados possuem diversidade morfológica e grau de arredondamento predominantemente anguloso e subanguloso, inferindo rochas-fonte metamórficas, ígneas e sedimentares, provenientes do Cráton Amazônico, Cinturão Araguaia, Bacia do Grajaú ou Sub-Bacia de Cametá, onde os sedimentos da Formação Barreiras e Pós-Barreiras se depositaram "on lap" sobre a Formação Ipixuna.

Palavras-chave: Bacia do Marajó. Sub-Bacia de Mocajuba. Minerais Pesados.

\begin{abstract}
The sedimentary rocks exposed as outcrop along the BR-150 highway, between the city of Jacundá and Goianésia do Pará, belong to the context of the southern margin of Mocajuba Sub-Basin, Marajó Basin, located in the Brazilian Equatorial Margin (BEM). Using the integrated faciological/ lithostratigraphic criteria, field data and heavy minerals, the rocks of the area were correlated to the Ipixuna, Barreiras and Post-Barreiras/Belterra Clay formations. Heavy Minerals study in these deposits allowed identifying the following mineralogical assemblages: zircon, tourmaline, rutile, staurolite, and kyanite, with high maturity ZTR index in all stratigraphic units. The analyzed grains stood out for their morphological diversity and predominant angular and subangular rounding, inferring metamorphic, igneous and sedimentary rocks from the Amazon Craton, Araguaia Belt, Grajaú Basin or Cametá Sub-Basin where the sediments from the Barreiras and Post-Barreiras Formation were deposited in "on lap" on the Ipixuna Formation.
\end{abstract}

Keywords: Marajó Basin. Mocajuba Sub-Basin. Heavy Minerals.

\section{INTRODUÇÃO}

O conhecimento das rochas sedimentares da região sudeste do estado do Pará é pouco desenvolvido, sendo a maioria provenientes de mapeamentos em escalas de 1:1.000.000 e 1:250.000 realizados pela Companhia de Pesquisa de Recursos Minerais (CPRM). Vasquez et al. (2008) admitem que as rochas sedimentares aflorantes nesta região fazem parte da Formação Itapecuru, enquanto Macambira \& Ricci (2014) as posicionam na Formação Ipixuna.

A área de estudo abrange as cidades de
Jacundá e Goianésia do Pará (BR-150), sudeste do estado do Pará (Figura 1B). Com base na disposição espacial, admite-se que os depósitos sedimentares se inserem no extremo sul da Bacia do Marajó, borda sul da Sub-Bacia de Mocajuba (Figura 1A) (Galvão, 1991; Villegas, 1994, Costa et al., 2002; Souza, 2012; Melo, 2013). Estes depósitos são geralmente maciços, com aspectos litoestratigráficos característicos, delimitados por superfícies de descontinuidades. As utilizações destas características litoestratigráficas associadas à análise de 
minerais pesados permitem uma discussão complementar sobre rocha-fonte destes depósitos em relação às áreas circunvizinhas, representadas por: rochas ígneas e metamórficas arqueanas/proterozoicas (Cráton Amazônico), rochas metamórficas proterozoicas (Cinturão Araguaia), rochas sedimentares

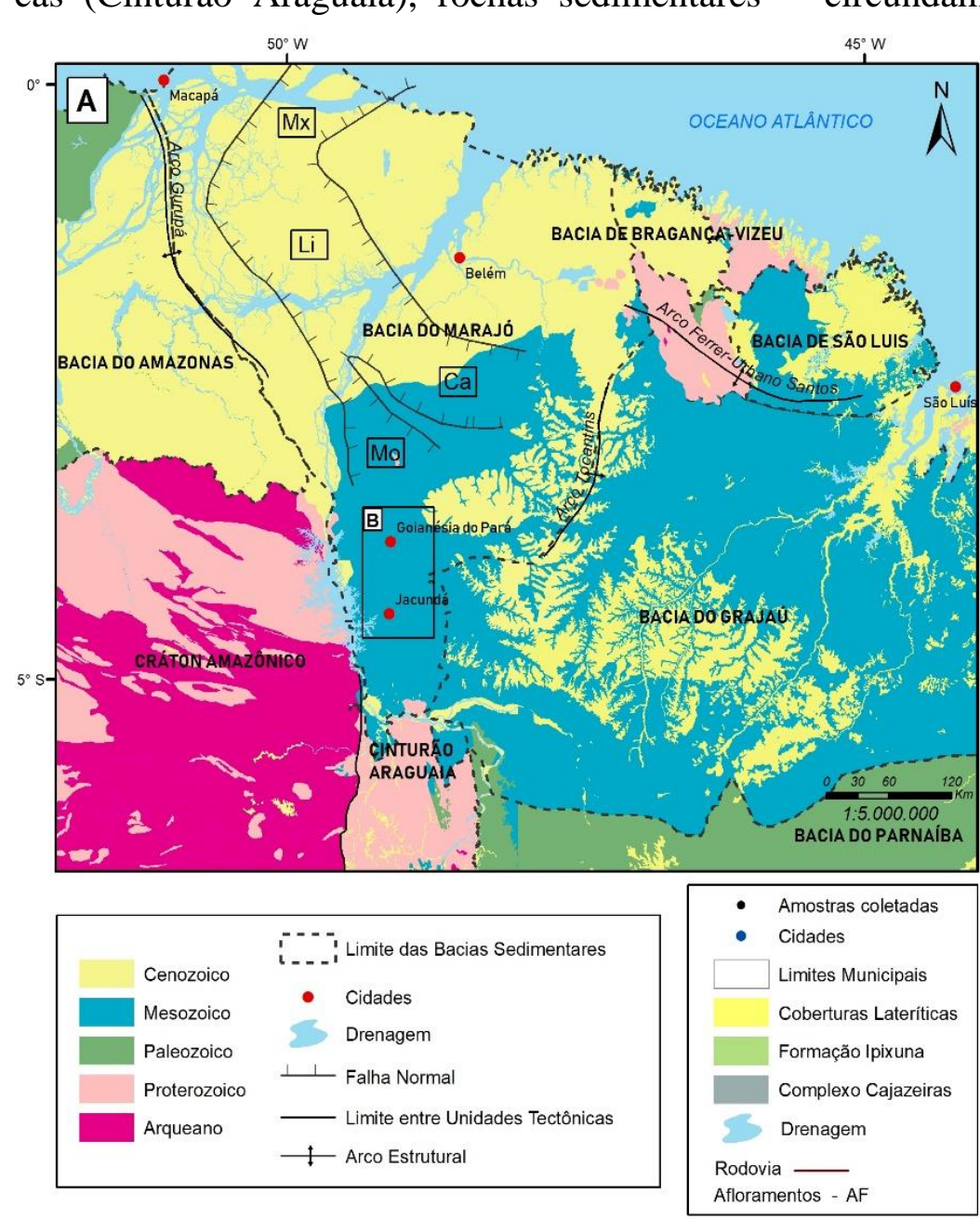

mesozoicas (Bacia do Grajau). Sendo assim, o presente trabalho tem como objetivo a correlação e caracterização dos depósitos sedimentares estudados ao longo da BR-150, com as unidades estratigráficas regionais, além da identificação das possíveis rochas-fonte que circundam a Sub-Bacia de Mocajuba.

Figura 1 - Contexto geológico e localização da área de estudo. A) Bacia do Marajó com suas respectivas Sub-Bacias (Mo - Sub-Bacia de Mocajuba, Ca - Sub-Bacia de Cametá, Li - Sub-Bacia de Limoeiro e Mx - Sub-Bacia de Mexiana) B) Área de estudo localizada entre as cidades de Jacundá e Goianésia do Pará, pontos de coleta de minerais pesados e afloramentos. Fonte: A) Modificado de Costa et al. (2002); Vasquez et al. (2008); B) Macambira \& Ricci (2014).

\section{CONTEXTO GEOLÓGICO}

A formação de bacias sedimentares mesozoicas brasileiras na região Meio-Norte do Brasil, tem sido atribuída a uma sucessão de estágios de rifteamento que deram origem aos oceanos Atlântico Central e Equatorial. Estas bacias passaram por várias etapas de evolução em diversos ambientes sedimentares ao longo do tempo geológico, configurando a Margem Equatorial Brasileira (MEQ) atual (Azevedo, 1991; Villegas, 1994; Costa et al., 2002; Silva et al., 2003; Soares Jr., 2007; Zalán \& Matsuda, 2007; Soares Jr. et al., 2008, 2011; Carneiro et al., 2012).
Como resultado dos processos distensivos, originou-se a Bacia do Marajó, representada por uma série de Sub-Bacias: Mexiana (Mx), Limoeiro (Li), Cametá (Ca) e Mocajuba (Mo) (Lima, 1987; Azevedo, 1991; Galvão, 1991; Villegas, 1994; Costa et al., 2002; Soares Jr., 2007; Soares Jr. et al., 2008; Zalán \& Matsuda, 2007; Soares Jr. et al., 2011). A Bacia do Marajó constitui um rift preenchido com cerca de $11 \mathrm{~km}$ de sequências sedimentares, depositadas desde o Eocretáceo até o presente, cujo embasamento são rochas do Pré-cambriano e remanescentes de sequências paleozoicas das bacias adjacentes 
(Avenius, 1988; Galvão, 1991; Villegas, 1994; Costa et al., 2002; Zalán \& Matsuda, 2007).

A Sub-Bacia de Mocajuba, área de estudo, localiza-se na porção sul da Bacia do Marajó e limita-se com a Sub-Bacia limoeiro (norte), Cráton Amazônico e Cinturão Araguaia (sul), e Sub-Bacia de Cametá e Bacia do Grajaú (leste) (Villegas, 1994; Zalán \& Matsuda, 2007). As características estratigráficas da Sub-Bacia de Mocajuba são correspondentes e correlacionadas com as sequências sedimentares aflorantes da Sub-Bacia de Cametá (Figura 2) (Góes, 1981; Costa et al., 2002; Santos Jr., 2002; Santos Jr. \& Rossetti, 2003; Nascimento \& Góes, 2005; Santos
Jr., 2006). Seu preenchimento sedimentar, definido em subsuperfície é representado pelas seguintes formações: Jacarezinho/Breves (AlboCenomaniano), Limoeiro (Cretáceo Superior/ Paleogeno), Marajó (Paleoceno/Mioceno) e Tucunaré/Pirarucu (Quaternário) (Lima, 1987; Galvão, 1991; Villegas, 1994). Em superfície constitui as formações: Itapecuru (AlboCenomaniano, Ipixuna (Cretáceo Superior/ Paleogeno), Barreiras (Mioceno), sedimentos Pós-Barreiras (Plio-Pleistoceno) e coberturas holocênicas (Lima et al., 1980; Villegas, 1994; Santos Jr., 2002, 2006; Vasquez et al., 2008; Souza \& Santos Jr., 2010).

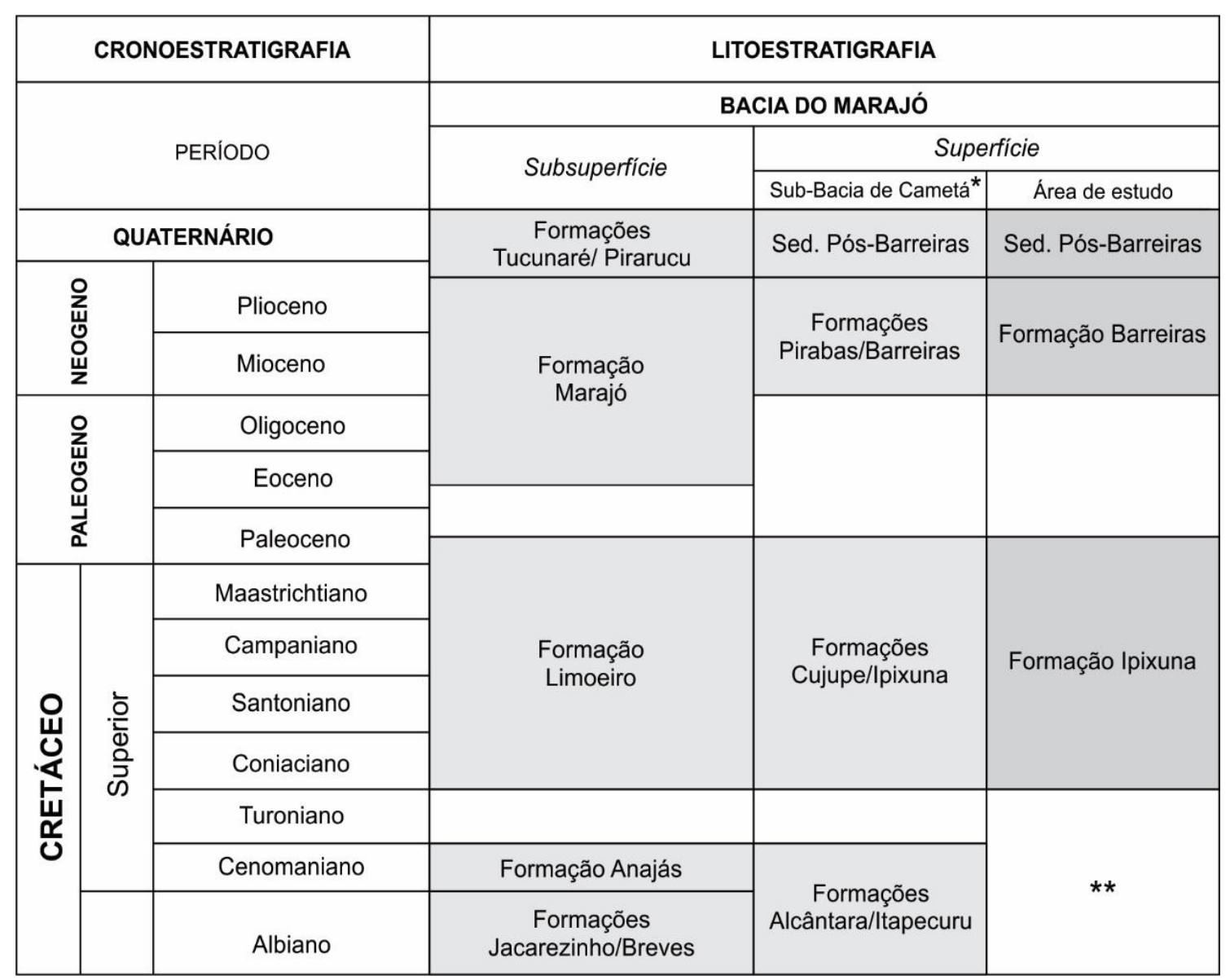

Figura 2 - Carta estratigráfica da Bacia do Marajó. Unidades definidas em subsuperfície e superfície, destacando as unidades encontradas na área de estudo. ** Unidade não aflorante. Fonte: Modificado de Villegas (1994); *Santos Jr. (2002; 2006).

Os litotipos característicos das unidades cretáceas em superfície e seus respectivos ambientes de sedimentação são: formações Alcântara/Itapecuru (Albo-Cenomaniano) formada por arenitos friáveis, localmente feldspáticos, com intercalações de argilitos e níveis de conglomerados em ambientes marinho raso e flúvio-deltaico (Góes, 1981; Villegas, 1994).

As formações Cujupe/Ipixuna (Cretáceo Superior/Paleogeno) apresentam conglome- rados maciços, arenitos estratificados e argilitos laminados, cauliníticos, oriundos de uma sedimentação em zona litorânea, em um ambiente fluvial e estuarino (Góes, 1981; Santos Jr., 2002; Santos Jr. \& Rossetti, 2003; Nascimento \& Góes, 2005; Santos Jr., 2006; Melo, 2013). A Formação Barreiras é representada por argilitos maciços/laminados, siltitos maciços/laminados, arenitos quartzosos com estratificação cruzada acanalada/tabular, 
bandamentos de maré, superfícies de reativação com recobrimentos argilosos e conglomerados, oriundos de sistema flúvio-estuarino (Santos Jr., 2002; Rossetti \& Santos Jr., 2004; Nascimento \& Góes, 2005; Santos Jr., 2006; Souza, 2012). Os Sedimentos Pós-Barreiras, consistem em areias, por vezes argilosas, formadas por processos principalmente eólicos (Rossetti et al., 2013) temporalmente correlacionáveis aos depósitos Argila de Belterra, os quais são representados por arenitos argilosos de coloração amarelada que podem chegar até $20 \mathrm{~m}$ de espessura (Kotschoubey \& Truckenbrodt, 1981)

\section{MATERIAIS E MÉTODOS}

Foram realizadas descrições de 9 afloramentos, croquis, documentação fotográfica e coleta sistemática de 11 amostras de sedimentos para a análise dos minerais pesados. Para a confecção dos mapas e croquis dos afloramentos foram utilizados os Softwares: ArcGis ${ }^{\circledR}$ 10.5, Google Earth Pro 7.3 e CorelDRAW X8 no Laboratório de Geoprocessamento da Universidade Federal do Sul e Sudeste do Pará.

As amostras dos sedimentos foram deslamadas, colocadas em Beckers e processadas no ultrassom objetivando a retirada de partículas finas. Em seguida, procedeu-se a secagem de aproximadamente $100 \mathrm{~g}$ de amostra a $80^{\circ} \mathrm{C}$ em estufa. Posteriormente, as amostras foram separadas nas frações granulométricas de 0,125 -0,063 $\mathrm{mm}$ (areia muito fina) para a obtenção de minerais pesados de acordo com Mange \& Maurer (1992).

Para a separação dos minerais pesados utilizou-se a técnica de separação por gravidade através de bromofórmio (densidade $2.89 \mathrm{~g} / \mathrm{ml}$ ), como líquido denso. Foram confeccionadas 11 lâminas representativas dos afloramentos, montadas em vidro com o auxílio de uma resina não birrefringente (bálsamo do Canadá, com índice de refração $=1.538$ ).

As lâminas de grãos foram descritas e contadas com o auxílio do microscópio petrográfico de luz transmitida (Zeiss Axioscop 40). Para a identificação dos minerais pesados foram utilizadas características tais como (forma, cor, pleocroísmo, clivagem, inclusões, alteração, zoneamento, etc.), com o auxílio de atlas de minerais pesados e de mineralogia óptica segundo Mange \& Mauer (1992), Nesse (2004) e Coutinho \& Coimbra (2005).

Para representar as frequências dos grãos de minerais pesados, obteve-se a contagem dos grãos utilizando a técnica de contagem em linhas (300 grãos de minerais transparentes, não opacos e não micáceos) por lâmina (Galehouse, 1971; Harwood, 1988). Na análise do grau de arredondamento dos grãos foi utilizada como base a tabela de Powers (1953), onde foram contados 100 grãos/lâmina, agrupados em duas categorias: anguloso e subanguloso $(A n+S a n)$ e subarredondado e arredondado $(\mathrm{Sa}+\mathrm{Ar})$. Por fim, para indicar o grau o de maturidade composicional empregou-se o índice ZTR de Hubert (1962), onde o cálculo foi feito através da somatória das percentagens individuais de zircão, turmalina e rutilo.

\section{APRESENTAÇÃO DE DADOS}

\section{Geologia da Área de Estudo}

Os pacotes sedimentares mapeados ao longo dos afloramentos 1 a 5 são caracterizados por: arenito argiloso maciço de coloração amarelada com marcas de raízes, fragmentos de lateritas de tamanho variando de seixos a blocos e relictos de lateritas colunar de coloração avermelhada; brecha maciça conglomerática de seixos de fragmentos de argilitos de coloração avermelhada, geralmente com textura mosqueada e perfil de solo composto por arenitos argiloso, maciço de coloração avermelhada, representando a base do afloramento (Figura 3). Estes pacotes representam depósitos sedimentares das formações Barreiras e Pós-Barreiras/Argila de Belterra.

A maioria dos perfis da Formação Barreiras apresentam cores mosqueadas, sedimentos areno-argilosos, arenoso e conglomeráticos, com diversidade de estratificações cruzadas oriundos de sistema flúvio-estuarino, os quais são delimitados no topo lateritas colunares sobrepostos por depósitos sedimentares da Formação Pós-Barreiras (Góes 1981; Arai et al., 1988, Rossetti et al., 1989, 1990; Santos Jr., 2002; Rossetti, 2004; Rossetti \& Santos Jr., 2004; Arai, 2006; Araújo et al., 2006; Furrier et al., 2006; Lima et al., 2006; Oliveira \& Silva, 2011; Souza, 2012). 

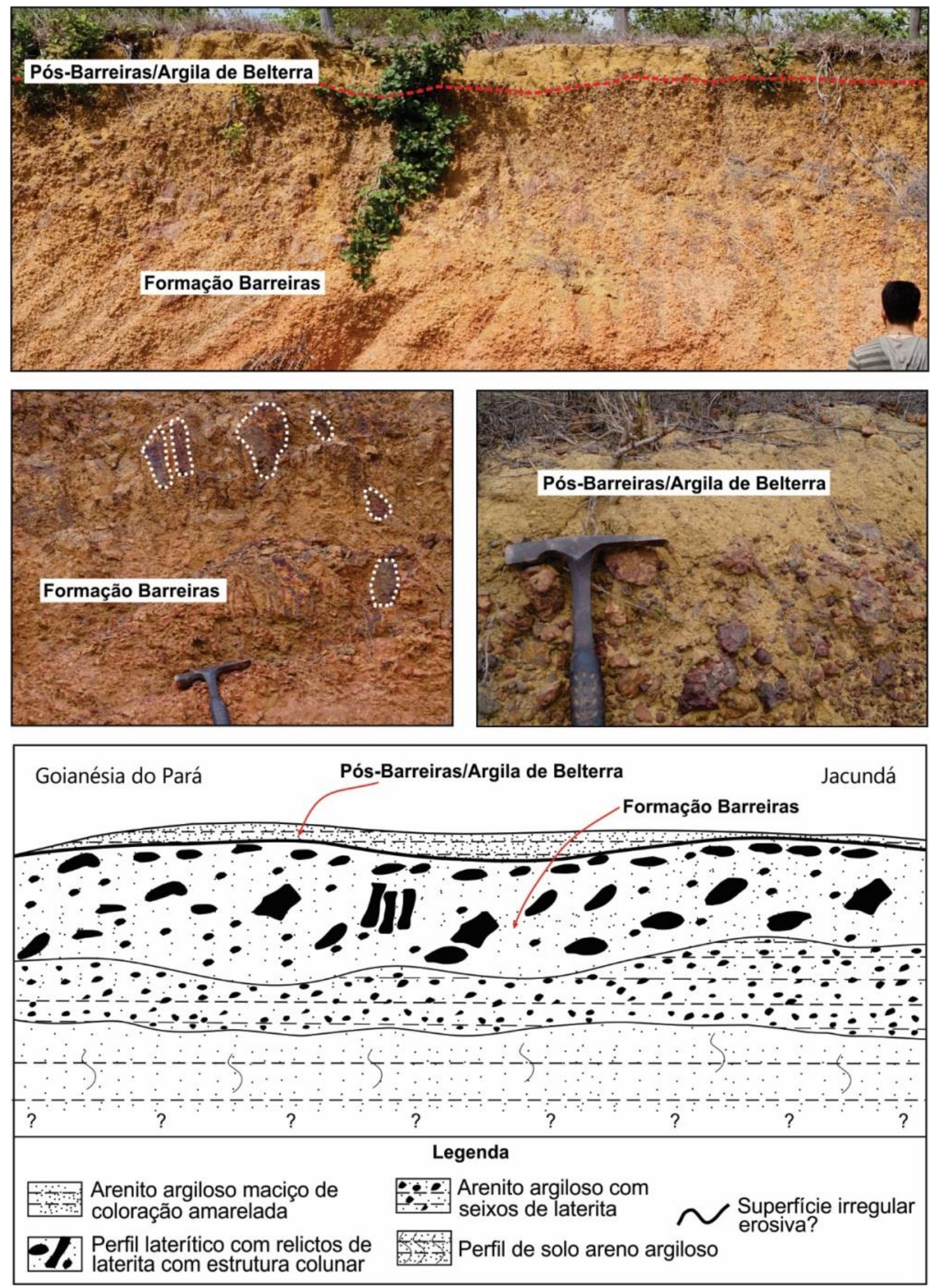

Figura 3 - Afloramentos correlacionáveis com a Formação Pós-Barreiras/Argila de Belterra e Formação Barreiras, com destaque para o arenito argiloso maciço de coloração amarelada e relictos de lateritas colunares. Suas principais características sedimentológicas foram representadas na forma de croqui.

As crostas lateríticas autóctones e/ ou com perfis lateríticos do topo da Formação Barreiras apresentam comumente desmantelamento físico, transformações químicas e mineralógicas, gerando resíduos lateríticos desmantelados como colúvio laterítico, solo e lags, onde estes ocorrem recobertos por latossolos amarelados. Estes latossolos, representados pela Formação Pós-Barreira ou Argila de Belterra, são caracterizados por sedimentos areno-argilosos, de coloração amarelada e granulometria de fina a grossa (Kotschoubey \& Truckenbrodt, 1981; Truckenbrodt \& Kotschoubey, 1981; Kotschoubey et al. 1987; Kotschoubey \& Truckenbrodt, 1994; Kotschoubey et al., 1997, 
2005; Oliveira \& Silva, 2011; Souza, 2012). As semelhanças estratigráficas destes depósitos em bacias circunvizinhas corroboram para esta interpretação. Os afloramentos 6 a 9 (Figura 4), encontrados ao longo da BR-150, mais próximos da cidade de Jacundá são caracterizados por: conglomerado de seixos de lateritas; arenito com seixos de quartzo; arenito esbranquiçado (cauliníticos) grosso a muito grosso com laminação plano paralela na base; granodecrescência que se encerram no topo e traços fósseis (Skolithos).
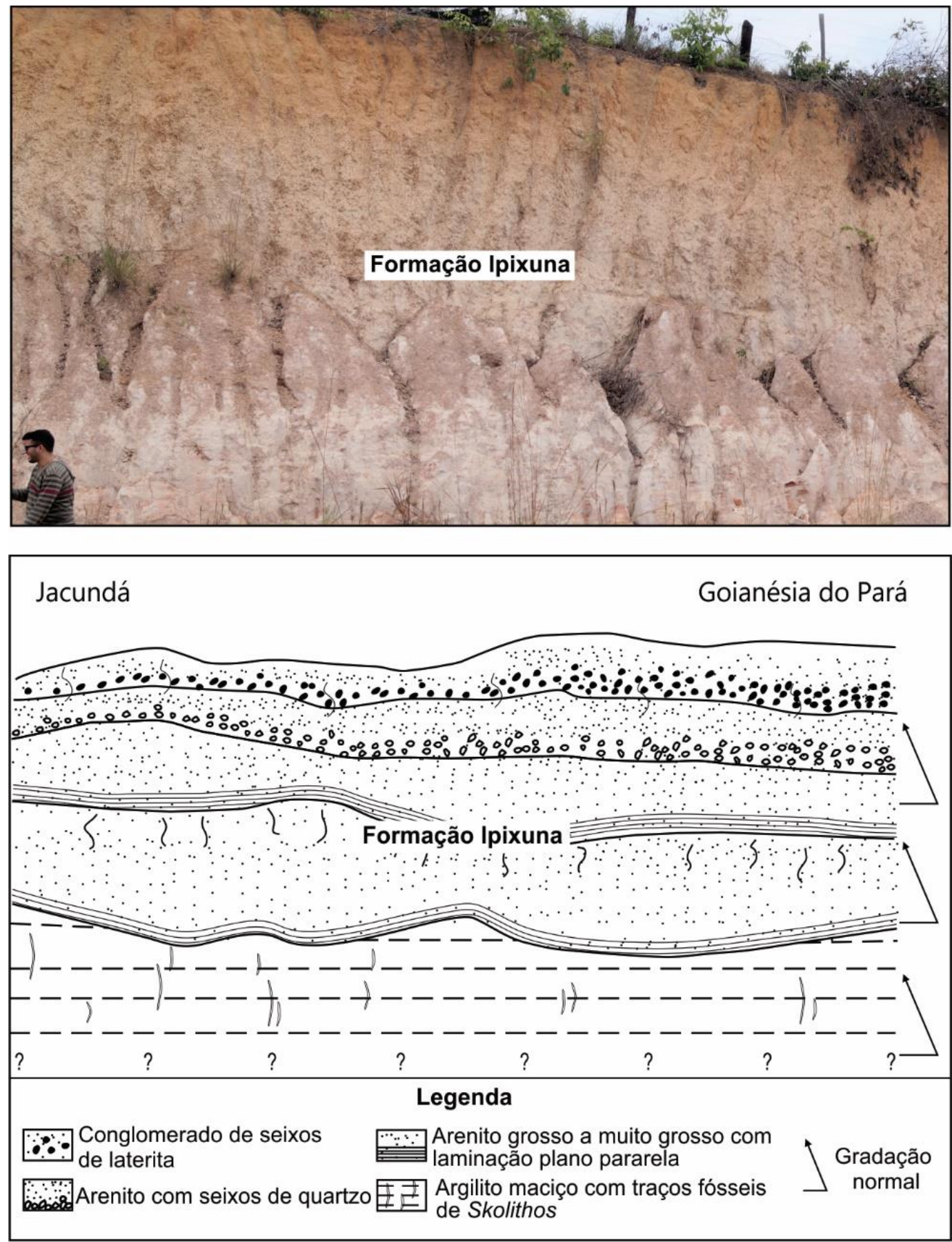

Figura 4. Afloramento com aspecto esbranquiçado correspondente ao arenito caulinítico, referente à Formação Ipixuna. Abaixo um croqui, evidenciando as principais características sedimentológicas descritas em campo.

Estas características são similares com as rochas da Formação Ipixuna, que ocorrem nas Bacia do Grajaú e Sub-Bacia de Cametá, constituída por depósitos arenitos siltitos e argilitos cauliníticos em decorrência da alteração de feldspatos para caulinita, de coloração esbranquiçada a avermelhada-amarelada, apresentando estratificação cruzada tabular, acanalada e festonada (Góes, 1981; Santos Jr., 2002; Santos Jr. \& Rossetti, 2003; Nascimento \& Góes, 2005; Santos Jr., 2006; Santos Jr. \& Rossetti, 2006; Vasquez et al., 2008). 
Uma vez que estes pacotes possuem estruturas sedimentares bem desenvolvidas, diferem-se texturalmente dos afloramentos anteriores, que se encontram predominantemente maciços e separados por superfície laterítica, representando assim, provavelmente, outra unidade estratigráfica.

Além de distinguir unidades estratigráficas utilizando critérios de superfícies de descontinuidades e aspectos faciológicos característicos das formações Barreiras e Ipixuna, representados por lateritas colunares e/ou desmanteladas, conteúdo siliciclásticos e feldspático-caulínico, respectivamente. A distribuição lateral dos pacotes sedimentares na área de estudo também revelaram descontinuidade.

O contato lateral abrupto entre as formações Barreiras e Ipixuna, observado na área de estudo
(Figura 5), está relacionado ao contexto neotectônico da região Amazônica, onde o mesmo afetou sequências sedimentares do Paleogeno/ Neogeno e Quaternário da região (Costa et al., 1996; Felipe, 2012; Soares Jr. et al., 2012).

Os depósitos da Formação Ipixuna (Cretáceo Superior - Paleogeno) sofreram processos neotectônicos, gerando espaço acomodacional para a sedimentação "on lap" da Formação Barreiras (Paleogeno/Neogeno) sobre a Formação Ipixuna.

Costa et al. (1996) também observaram a distribuição dessas formações em faixas alternadas na região nordeste do Pará, entre as cidades de Mãe do Rio e São Miguel do Guamá, considerando esta disposição decorrente de estruturas do Quaternário assinaladas por deslocamentos verticais ao longo de falhas normais.
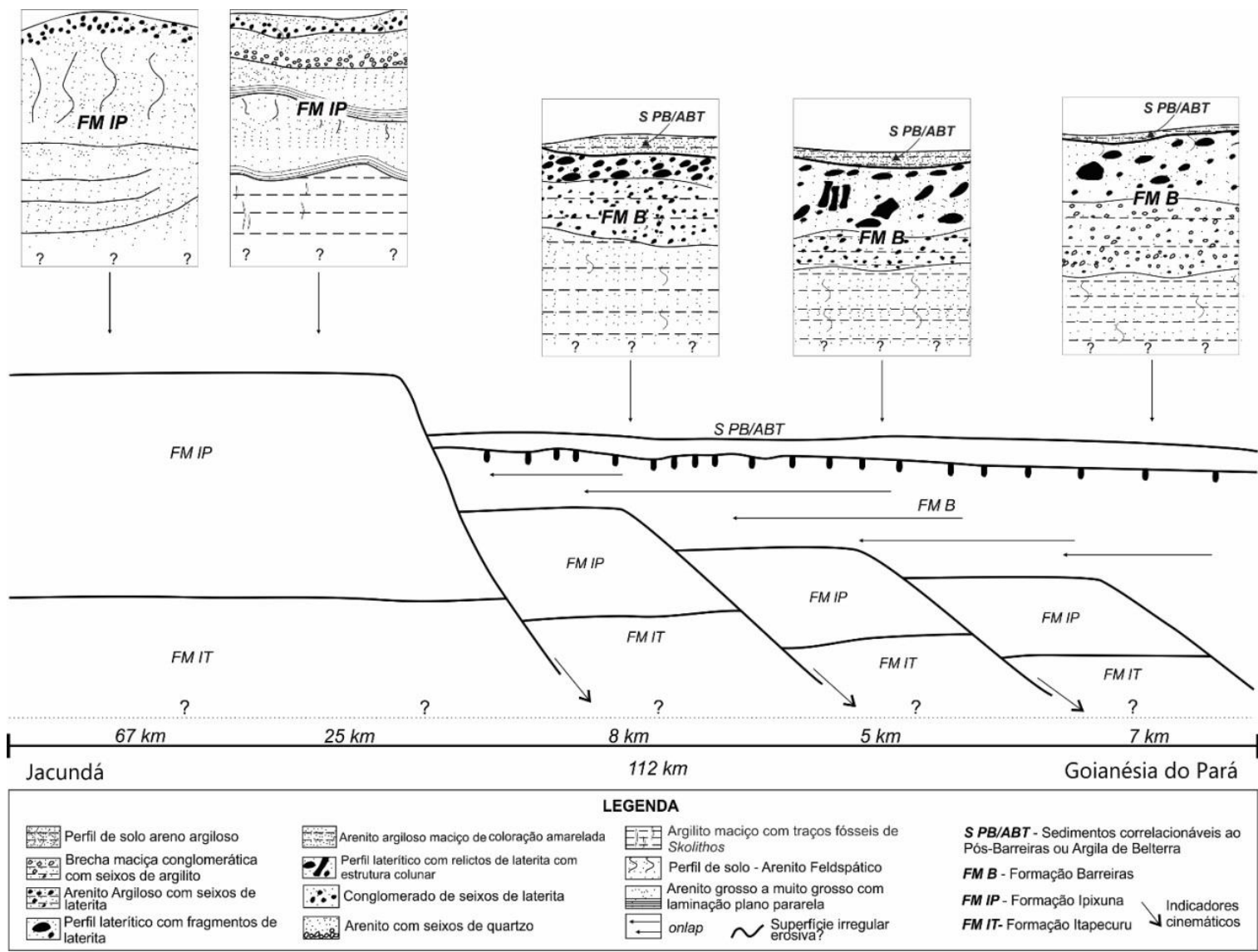

Figura 5 - Esquema ilustrando o sistema de gráben, com as respectivas formações encontradas na área de estudo, caracterizando uma provável causa da mudança abrupta lateral dos pacotes sedimentares encontrados ao longo da BR150, entre as cidades de Jacundá e Goianésia do Pará.

\section{Minerais Pesados}

Os minerais pesados (grãos com densidade > $2.8 \mathrm{~g} . \mathrm{cm}^{3}$ ) são componentes que perfazem cerca de $\sim 1 \%$ em uma amostra e constituem uma ferramenta muito útil para o estudo de proveniência (Mange \& Maurer, 1992). Estes minerais não só refletem a composição do material de origem, área-fonte, mas registram uma série de processos durante os ciclos sedimentares que operam durante o intemperismo, transporte, deposição e diagênese (Morton \& Hallsworth, 1998; Nascimento \& 
Góes 2005; Morton, 2012). Além disso, a ordem de estabilidade mecânica e química representa um fator importante na análise de minerais pesados, e são classificadas em: ultra-estáveis, estáveis, moderadamente estáveis, instáveis e muito instáveis (Pettijohn et al., 1973) (Tabela 1).

Tabela 1. Ordem de estabilidade dos minerais pesados.

\begin{tabular}{c|c|c|c|c}
\hline Ultra-Estáveis & Estáveis & $\begin{array}{c}\text { Moderadamente } \\
\text { Estáveis }\end{array}$ & Instáveis & Muito Instáveis \\
\hline Rutilo & $\begin{array}{c}\text { Apatita } \\
\text { Granada }\end{array}$ & Epídoto & Hornblenda & Olivina \\
Zircão & Cianita & Actinolita & \\
Turmalina & Estaurolita & $\begin{array}{c}\text { Granada } \\
\text { (alto Fe) }\end{array}$ & Andaluzita & \\
& Zoisita & Sillimanita & Diopsídio & \\
\hline
\end{tabular}

Fonte: Modificado de Pettijohn et al. (1973).

A assembleia de minerais pesados transparentes não micáceos da região de estudo mostram uma pequena diversidade mineralógica e incluem zircão, turmalina, rutilo, estaurolita, cianita e anatásio (Tabela 2).

Tabela 2. Frequência dos minerais pesados (\%) encontrados nas amostras, correlacionadas com os sedimentos e formações geológicas da área de estudo. Onde, F.P/ABT = Formação Pós-Barreiras/ Argila de Belterra, F.B.= Formação Barreiras, F. IP = Formação Ipixuna e $\mathrm{N}$ = número total de grãos contados na lâmina.

\begin{tabular}{|c|c|c|c|c|c|c|c|c|}
\hline & AMOSTRA & Zircão & Turmalina & Rutilo & Estautolita & Cianita & Anatásio & $\mathbf{N}$ \\
\hline \multirow{2}{*}{ F.P/ABT. } & $M T-02$ & 66,3 & 7,7 & 21,3 & 4,7 & 0 & 0 & 300 \\
\hline & MT-06 & 83,7 & 4 & 7 & 5,3 & 0 & 0 & 300 \\
\hline \multirow{4}{*}{ F. B. } & $M T-01$ & 89,3 & 4,3 & 5,7 & 0,7 & 0 & 0 & 300 \\
\hline & $M T-03$ & 86 & 8,7 & 4 & 1,3 & 0 & 0 & 300 \\
\hline & $M T-04$ & 94,7 & 2,3 & 2,3 & 0,3 & 0 & 0 & 300 \\
\hline & $M T-05$ & 96,3 & 2,3 & 1 & 0,3 & 0 & 0 & 300 \\
\hline \multirow{5}{*}{ F. IP. } & MT-07 & 99,3 & 0 & 0 & 0,7 & 0 & 0 & 300 \\
\hline & MT-08 & 98 & 0,7 & 1,3 & 0 & 0 & 0 & 300 \\
\hline & MT-09 & 88,7 & 2,3 & 4 & 3,7 & 1,3 & 0 & 300 \\
\hline & $M T-10$ & 87,7 & 7 & 2 & 2,7 & 0,7 & 0 & 300 \\
\hline & $M T-11$ & 83 & 7,7 & 4,3 & 3,3 & 1,3 & 0,3 & 300 \\
\hline
\end{tabular}

$\mathrm{Na}$ análise do grau de arredondamento com base em Powers (1953), foram agrupadas duas categorias: anguloso e subanguloso $(A n+\operatorname{San})$ e subarredondado e arredondado ( $\mathrm{Sa}+\mathrm{Ar})$ (Tabela $3)$. Os aspectos texturais dos minerais pesados (p.e. arredondamento, esfericidade, coloração, zoneamento) são similares em todas as amostras (Figura 6), variando em proporção ao longo das unidades estratigráficas: Formações Ipixuna, Barreiras e Pós-Barreiras. O zircão é o mineral mais abundante e está presente em todas as lâminas descritas, fazendo parte dos minerais ultra-estáveis. Possui média de $88,5 \%$ e frequência que varia de 66,3 a $99,3 \%$. Nas lâminas descritas os grãos apresentam-se incolores e com tonalidades que variam de castanho, amarelo e levemente rosado, alguns grãos estão encobertos por cimento ferruginoso dando uma coloração avermelhada ao mineral. Além disso, alguns zircões exibem zoneamento, pequenas inclusões minerais e encontram-se fraturados. Na Formação Ipixuna, os grãos em sua maioria apresentam-se prismáticos angulosos e subangulosos, com predominância de $73 \%$, já os grãos arredondados e subarredondados perfazem cerca de $20 \%$. Na Formação Barreiras, o índice de grãos angulosos e subangulosos são de $61,5 \%$, o que possui caráter ainda predominante comparado com os grãos arredondados e subarredondados 31\%. Nos sedimentos Pós-Barreiras/Argila de Belterra os grãos angulosos e subangulosos estão em torno de $51 \%$ e arredondados a subarredondados $38 \%$. 
Tabela 3. Grau de arredondamento das amostras analisadas, utilizando como base a tabela de Powers (1953). Onde,

F.P/ABT = Formação Pós-Barreiras/Argila de Belterra, F.B.= Formação Barreiras, F. IP = Formação Ipixuna, $\mathrm{An}+\mathrm{San}=$ anguloso + subanguloso, $\mathrm{Sa}+\mathrm{Ar}=$ subarredondado+arredondado e $\Sigma \mathrm{G} . \mathrm{A} .=$ soma do grau de arredondamento $(\mathrm{An}+\mathrm{San}$ e $\mathrm{Sa}+\mathrm{Ar})$ de cada amostra de acordo com mineral.

\begin{tabular}{|c|c|c|c|c|c|c|c|c|c|c|c|c|c|}
\hline & \multirow{2}{*}{$\begin{array}{c}\begin{array}{c}\text { AMOS } \\
\text { TRA }\end{array} \\
\text { G.A }\end{array}$} & \multicolumn{2}{|c|}{ Zircão } & \multicolumn{2}{|c|}{ Turmalina } & \multicolumn{2}{|c|}{ Rutilo } & \multicolumn{2}{|c|}{ Estaurolita } & \multicolumn{2}{|c|}{ Cianita } & \multicolumn{2}{|c|}{$\Sigma$ G.A } \\
\hline & & $\begin{array}{c}\text { An+ } \\
\text { San }\end{array}$ & $\begin{array}{c}\mathrm{Sa}+ \\
\mathbf{A r}\end{array}$ & $\begin{array}{l}\text { An+ } \\
\text { San }\end{array}$ & $\begin{array}{c}\text { Sa+ } \\
\mathbf{A r}\end{array}$ & $\begin{array}{c}\text { An+ } \\
\text { San }\end{array}$ & $\begin{array}{r}\text { Sa+ } \\
\mathbf{A r}\end{array}$ & $\begin{array}{c}\text { An+ } \\
\text { San }\end{array}$ & $\begin{array}{c}\text { Sa+ } \\
\mathbf{A r}\end{array}$ & $\begin{array}{c}\text { An+ } \\
\text { San }\end{array}$ & $\begin{array}{c}\text { Sa+ } \\
\text { Ar }\end{array}$ & $\begin{array}{c}\text { An+ } \\
\text { San }\end{array}$ & $\begin{array}{c}\mathrm{Sa}+ \\
\mathrm{Ar}\end{array}$ \\
\hline \multirow{2}{*}{$\begin{array}{c}\text { F.P./ } \\
\text { ABT } \\
.\end{array}$} & MT-02 & 47 & 39 & 2 & 3 & 2 & 2 & 5 & 0 & 0 & 0 & 56 & 44 \\
\hline & MT-06 & 55 & 37 & 0 & 1 & 0 & 5 & 0 & 2 & 0 & 0 & 55 & 45 \\
\hline \multirow{4}{*}{ F. B. } & MT-01 & 47 & 38 & 3 & 7 & 2 & 2 & 1 & 0 & 0 & 0 & 53 & 47 \\
\hline & MT-03 & 67 & 22 & 0 & 6 & 4 & 0 & 1 & 0 & 0 & 0 & 72 & 28 \\
\hline & MT-04 & 61 & 37 & 0 & 6 & 4 & 0 & 1 & 0 & 0 & 0 & 62 & 38 \\
\hline & MT-05 & 71 & 26 & 0 & 3 & 0 & 0 & 0 & 0 & 0 & 0 & 71 & 29 \\
\hline \multirow{5}{*}{$\begin{array}{l}\text { F. } \\
\text { IP. }\end{array}$} & MT-07 & 79 & 21 & 0 & 0 & 0 & 0 & 0 & 0 & 0 & 0 & 79 & 21 \\
\hline & MT-08 & 80 & 18 & 0 & 0 & 0 & 0 & 0 & 0 & 0 & 0 & 80 & 20 \\
\hline & MT-09 & 78 & 14 & 0 & 0 & 0 & 0 & 0 & 0 & 0 & 0 & 80 & 18 \\
\hline & MT-10 & 61 & 28 & 0 & 5 & 2 & 1 & 2 & 0 & 1 & 0 & 66 & 34 \\
\hline & MT-11 & 67 & 18 & 6 & 2 & 2 & 0 & 3 & 0 & 2 & 0 & 80 & 20 \\
\hline
\end{tabular}
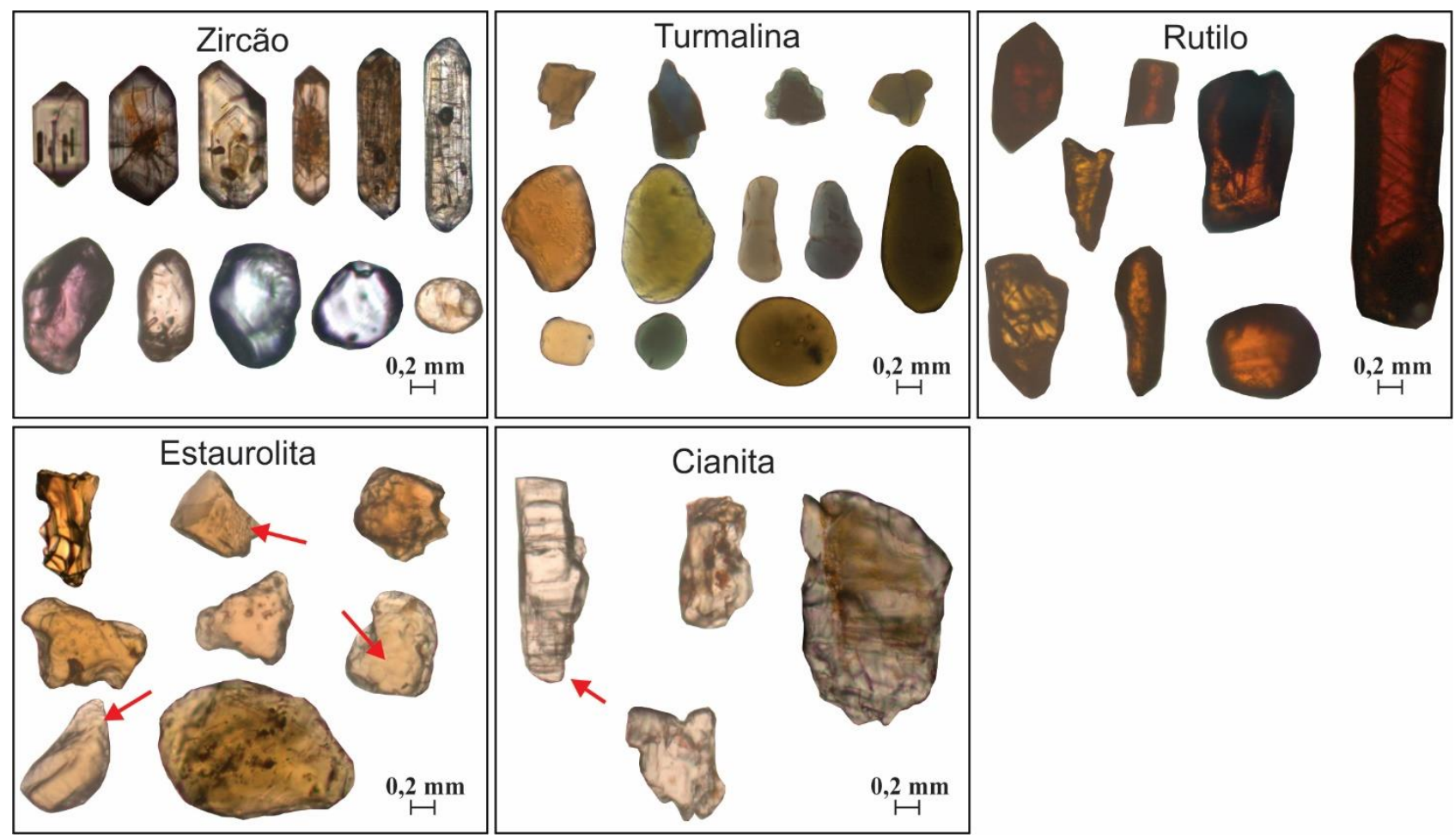

Figura 6. Fotomicrografia (luz natural) exibindo as variações dos aspectos texturais dos principais minerais pesados encontrados na área de estudo: zircão, turmalina, rutilo, estaurolita (seta indicando textura 'crista de galo') e cianita (seta indicando estrutura 'step-like', típica deste mineral).

A turmalina está presente na maioria das lâminas descritas e também faz parte dos minerais ultra-estáveis. Constitui uma média de 4,3\% com frequência de 8,7 a $0,7 \%$ entre os minerais pesados descritos. Os grãos exibem forte a moderado pleocroísmo, onde as cores variam de verde, verde claro, amarelo e castanho.

$\mathrm{Na}$ Formação Ipixuna, o grau de arredondamento possui valores muito próximos, as turmalinas angulosas e subangulosas perfazem cerca de $6 \%$ e as que possuem arredondadas e subarredondadas $5 \%$. Na Formação Barreiras, há uma diferença sútil no grau de arredondamento, onde os grãos que 
se apresentam angulosos a subangulosos são de $3 \%$, já os arredondados a subarredondados $6 \%$. Nos sedimentos Pós-Barreiras/Argila de Belterra, os valores dos grãos mostram-se muito próximos, onde os angulosos e subangulosos perfazem $2 \%$ e os arredondados e subarredondados $3 \%$.

$\mathrm{O}$ rutilo possui uma média de $4,8 \%$ e constitui 1 a 21,3\% dos minerais pesados descritos. Assim como o zircão e turmalina também faz parte dos minerais pesados mais resistentes (ultra-estáveis). As cores dos grãos variam de marrom avermelhado, marrom e marrom amarelado. Além do relevo alto as bordas escuras são características desse mineral, devido o índice de refração extremamente alto (Mange \& Mauer, 1992). Na Formação Ipixuna, o grau de arredondamento exibe valores quase que similares, os grãos angulosos e subangulosos perfazem cerca de $2 \%$ e arredondados e subarredondados $1 \%$.

Na Formação Barreiras, os grãos angulosos e subanguloso possuem valores de $4 \% \mathrm{e}$ arredondados e subarredondados 2\%. Já nos sedimentos Pós-Barreiras/Argila de Belterra os grãos angulosos e subangulosos perfazem $2 \% \mathrm{e}$ arredondados e subarredondados $4 \%$.

A estaurolita faz parte dos minerais estáveis e possuem uma média de $2,1 \%$ com frequência de 0,3 a $5,3 \%$ dos minerais pesados descritos. Os grãos possuem tonalidades que variam de amarela a amarelo pálido, alguns grãos apresentam-se levemente pleocroicos. Ocorrem ainda texturas que provavelmente são provocadas por dissolução como: superfícies corroídas identificadas como 'crista de galo', característica da estaurolita (Nascimento \& Góes, 2007).

Praticamente em todas as formações da área de estudo, o grau de arredondamento da estaurolita apresenta-se anguloso e subanguloso. Na Formação Ipixuna os grãos são predominantemente angulosos e subangulosos, perfazem cerca de 3\%. Na Formação Barreiras também há o predomínio de grãos angulosos e subangulosos 1\%. Nos sedimentos PósBarreiras ocorrem grãos tanto angulosos e subangulosos $5 \%$ quanto arredondados $\mathrm{e}$ subarredondados $2 \%$.

A cianita é classificada como moderadamente estável e apresenta-se menos abundante, com uma média de $0,3 \%$ e frequências que variam de 0,7 a $1,3 \%$. Os grãos apresentam-se incolores á cinza amarelado, relevo alto e ocorrem com hábitos prismáticos tabulares. Alguns grãos exibem partições e estrutura 'step-like' relacionada com a clivagem, além de apresentar extinção inclinada que distingue dos minerais andalusita e sillimanita (Mange \& Mauer, 1992). Em relação ao grau de arredondamento dos grãos de cianita, só ocorre nas amostras da Formação Ipixuna, onde os grãos são predominantemente angulosos e subangulosos e perfazem cerca de $2 \%$.

\section{Índice de Maturidade Mineralógica, ZTR}

Alguns parâmetros na análise de minerais pesados fornecem um bom reflexo das características da área fonte. Um desses parâmetros corresponde ao índice de zircãoturmalina-rutilo (ZTR), que é caracterizado pela soma em percentual desses minerais entre os demais transparentes e não-micáceos. Este índice define quantitativamente a maturidade mineralógica da assembleia dos minerais pesados em arenitos (Hubert, 1962). A medida que o índice ZTR aumenta, ocorre um decréscimo da variedade de minerais pesados transparentes (Hubert, 1962).

Nas amostras referentes aos sedimentos da área de estudo, os valores de ZTR variam de 94,7 a 100\% (Tabela 4). Na Formação Ipixuna o índice ZTR é em média 97\%, na Formação Barreiras $99 \%$ e nos sedimentos PósBarreiras/Argila de Belterra 95\%, caracterezando assim sedimentos em geral de maturidade alta, principalmente pelo alto conteúdo de zircão nas amostras, bem como outros minerais ultra-estáveis que compõe este índice.

\section{DISCUSSÕES, INTERPRETAÇÕES E RESULTADOS}

Elementos faciológicos/estratigráficos e estudo de minerais pesados nos depósitos sedimentares que afloram no trecho de Jacundá até Goianésia do Pará, quando analisados de forma isolada, são ineficientes na individualização de unidades estratigráficas. A aplicação de análises de fácies na reconstrução de ambientes deposicionais destes depósitos é inviável devido a quase ausência de estruturas sedimentares e geometria de corpos sedimentares, bem como suas relações laterais e verticais, o que impossibilita o reconhecimento 
comparativo destes depósitos com unidades estratigráficas aflorantes em bacias sedimentares circunvizinhas (p.e., Bacias de Grajaú e Sub-Bacia de Cametá).

Similarmente, os altos índices ZTR, maiores que $90 \%$ em todas as amostras analisadas, indicam alta maturidade dos sedimentos de todas as unidades estratigráficas, dificultando a distinção dos depósitos sedimentares apenas por este parâmetro.
Porém, a utilização de critérios faciológicos estratigráficos e estudo de minerais pesados de forma integrada permitem sustentar que na área de estudo ocorre três unidades estratigráficas: Formação Ipixuna, Formação Barreiras e os sedimentos Pós-Barreiras/Argila Belterra. Mudanças sutis nas percentagens de alguns minerais pesados quando analisados juntamente com os índices ZTR, possibilitaram diferenciar unidades estratigráficas.

Tabela 4 - Índice de maturidade mineralógica (ZTR = Zircão+Turmalina+Rutilo).

\begin{tabular}{c|c|c}
\hline & AMOSTRA & ZTR (\%) \\
\hline \multirow{4}{*}{$\boldsymbol{F . P} / \boldsymbol{A B T} \boldsymbol{B}$} & $M T-02$ & 95,3 \\
\cline { 2 - 3 } & $M T-06$ & 94,7 \\
\hline \multirow{4}{*}{$\boldsymbol{F . B}$} & $M T-01$ & 99,3 \\
\cline { 2 - 3 } & $M T-03$ & 98,7 \\
\cline { 2 - 3 } & $M T-04$ & 99,3 \\
\cline { 2 - 3 } & $M T-05$ & 99,7 \\
\hline \multirow{4}{*}{$\boldsymbol{F . I P .}$} & $M T-07$ & 99,3 \\
\cline { 2 - 3 } & $M T-08$ & 100 \\
\cline { 2 - 3 } & $M T-09$ & 95,0 \\
\cline { 2 - 3 } & $M T-10$ & 96,7 \\
\cline { 2 - 3 } & $M T-11$ & 95,0 \\
\hline
\end{tabular}

A Formação Ipixuna (sedimentos esbranquiçados arenosos ou argilosos), representada pelas amostras MT-07, MT-08, MT-09, MT-10 e MT-11, apresentam índices ZTR elevados variando de 99,3 a $100 \%$ nas amostras MT-07 e 08, e 96,7 a 95\% e nas amostras MT-09, 10 e 11. Apesar da diferença nos índices ZTR, os depósitos sedimentares descritos em campo possuem as mesmas características sedimentológicas evidenciado pelo aspecto esbranquiçado observado nos afloramentos, marcado pela presença de arenitos e argilitos feldspáticos caulinizados. $\mathrm{O}$ alto índice de ZTR nas amostras MT-07 e 08 é explicado pela proximidade ao topo da superfície erosiva laterítica que encerra os depósitos da Formação Ipixuna. As amostras MT-09, 10 e 11, as quais registram o aparecimento da cianita 0,7 a $1,3 \%$ e anatásio $0,3 \%$, acompanhado do zircão, rutilo, turmalina e estaurolita, formam uma assembleia de minerais pesados provavelmente mais preservada, o que justificaria o índice ZTR menor quando comparado às amostras MT-07 e
08. Esta interpretação baseia-se no fato que estas amostras ocorrem nos pacotes sedimentares mais inferiores da Formação Ipixuna, distantes da superfície erosiva laterítica.

Os sedimentos correlacionáveis a Formação Barreiras (sedimentos areno argilosos avermelhados friáveis com a presença de lateritas), representados pelas amostras MT-01, MT-03, MT-05 e MT-06, apresentam índices ZTR de 98,7 a 99,7\%, com percentuais de minerais de estaurolita, em torno de 0,7 a $0,3 \%$.

Os depósitos correlacionáveis aos sedimentos Pós-Barreiras/Argila de Belterra (arenitos argilosos de coloração amarelada) são representados pelas amostras MT-02 e MT-06. Estas possuem índices ZTR de 94,3 e 95,3\%. É marcante a presença de estaurolita com assinaturas mais altas 4.7 a $5.3 \%$ comparadas com a ocorrência deste mineral nas outras amostras analisadas.

Além de ser uma distinção marcante em relação aos outros depósitos da área, a estaurolita é um mineral que acompanha a 
turmalina, com valores $4 \%$ e $7 \%$. Segundo Kotschoubey et al. (2005) e Oliveira \& Silva (2011), estes minerais possuem presença marcante nas Formações Pós-Barreiras/Argila Belterra.

Minerais pesados encontrados em rochas sedimentares são geralmente compostos por diversas espécies de minerais, e cada grão transmite sua própria história. As propriedades desses minerais permitem que tenhamos uma visão geral do caráter petrológico da fonte dos sedimentos e possibilita esta associação através de suas características.

As assembleias de minerais encontrados nos depósitos aflorantes na região relacionadas às formações Ipixuna, Barreiras e PósBarreiras/Argila de Belterra, sugerem áreasfontes ígneas, metamórficas e sedimentares. Apesar do índice ZTR apresentar respostas de alta maturidade em todas as unidades estratigráficas, os grãos analisados destacam-se por sua diversidade morfológica e grau de arredondamento, o que sugere uma mistura de sedimentos com trajetórias diferentes.

O zircão se faz presente em quase todos os tipos de rochas, exceto em rochas máficas e rochas cabornáticas metamorfizadas, pode ser encontrado em uma variedade de sedimentos clásticos como parte da fração de minerais pesados (Mange \& Mauer, 1992; Nesse, 2013). $\mathrm{Na}$ área de estudo os grãos apresentam-se angulosos, subangulosos, arredondados e subarredondados o que sugere fontes diferentes. As formas prismáticas com terminações bipiramidais e bordas angulosas, geralmente apresentam-se zonados, estes sugerem além de uma fonte mais proximal, prováveis fontes graníticas (Góes, 1981). Segundo Tomita (1954), a presença de zircão de coloração rosa a violeta é derivada de gnaisses arqueanos ou granitos onde a cor é considerada radiogênica, esta variedade ocorre em algumas amostras da área. Já os grãos que se encontram subarredondados-arredondados podem ser derivados de sedimentos de outros ciclos sedimentares.

A turmalina é um mineral característico de granitos pegmatíticos e acessório comum em granitos e granodioritos, comum como mineral acessório em xisto, gnaisse e filito (Mange \& Mauer, 1992; Nesse, 2013). Grãos de turmalina policíclica erodidas de depósitos siliciclásticos pré-existentes são arredondados a bem arredondados e estão associadas com zircão e rutilo (Mange \& Mauer, 1992; Nesse, 2013). Estas últimas são encontradas com maior quantidade na maioria dos depósitos sedimentares da área.

$\mathrm{O}$ rutilo comumente ocorre como mineral acessório em diversas rochas ígneas (principalmente pegmatíticas) e metamórficas, embora seja mais difundido em rochas metamórficas como xistos, gnaisses e anfibolitos (Mange \& Mauer, 1992; Nesse, 2013). Os grãos da área de estudo apresentamse diversificados quanto ao grau de arredondamento, aqueles prismáticos e angulosos provavelmente são derivados de rochas mais próximas da área fonte, já os arredondados compreendem fontes mais distais ou pertencentes a mais de um ciclo sedimentar.

A estaurolita e cianita são exclusivas de rochas metamórficas. A estaurolita está presente em mica xistos, derivados de sedimentos argilosos e menos frequente em gnaisses (Mange \& Mauer, 1992; Nesse, 2013). A cianita ocorre em gnaisses, granulitos e xistos pelíticos, considerada como um indicador de zona de metamorfismo mais alto comparada com a estaurolita (Mange \& Mauer, 1992; Nesse, 2013). Esta última está presente apenas nas amostras referentes à Formação Ipixuna. Ambos grãos em sua maioria ocorrem prismáticos e angulosos o que pode-se atribuir a uma deposição direta do embasamento, o que justifica a existência desses minerais nos sedimentos analisados já que estes são de difícil preservação (estáveis) comparado com os outros minerais que ocorrem na área de estudo.

$\mathrm{O}$ caráter anguloso e subanguloso dos minerais pesados das formações Ipixuna, Barreiras e Pós-Barreiras são em média $77 \%$, $64,5 \%$ e $55,5 \%$, respectivamente, denotando grande contribuição de uma rocha-fonte mais proximal, ígnea ou metamórfica, ligada ao Cráton Amazônico ou Cinturão Araguaia (Figura 7). A ocorrência similar da assembleia de minerais pesados ao longo de todas as formações Ipixuna, Barreiras e Pós-Barreiras associada ao aumento no grau de arredondamento em relação as unidades estratigraficamente mais jovens sugere suprimento sedimentar continuo durante o preenchimento sedimentar da Sub-Bacia de 
Mocajuba, com aumento na contribuição de rochas sedimentares, pelo menos desde o Cretáceo superior até o Plio-Pleistoceno, conferindo um caráter multicíclico cada vez maior nas unidades mais jovens. As formas mais arredondadas sugerem, além de transporte maior, fontes mais distais, podendo ser oriundos das unidades estratigráficas basais de outras bacias (p.e. Grajaú ou Sub-Bacia Cametá).

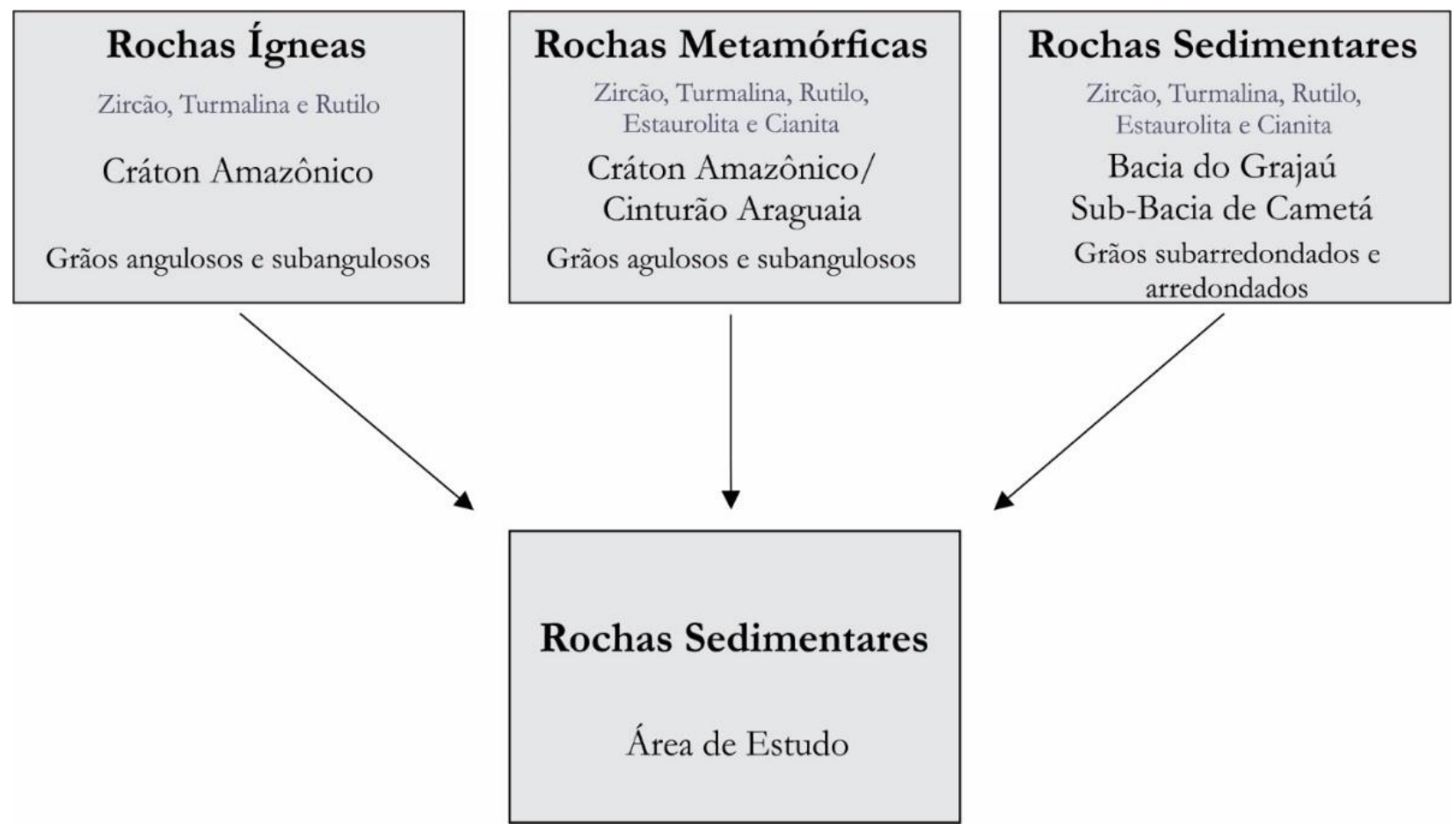

Figura 7. Esquema exibindo de maneira geral as prováveis rochas-fonte com base na análise dos minerais pesados da área de estudo.

\section{CONCLUSÃO}

O estudo dos aspectos litoestratigráficos e análise de minerais pesados nos depósitos sedimentares aflorantes ao longo da BR-150, entre as cidades de Jacundá e Goianésia do Pará, permitiram o reconhecimento de três formações: Ipixuna, Barreiras e PósBarreiras/Argila de Belterra, divergindo dos mapeamentos regionais, que atribuem as formações Pequizeiro, Itapecuru e Codó ou apenas a Formação Ipixuna.

A assembleia de minerais pesados principal, comuns em todas as formações, Ipixuna, Barreiras e Pós-Barreiras/Argila de Belterra são: zircão, turmalina, rutilo, estaurolita e cianita, as quais apresentam aspectos texturais, grau de arredondamento e índice de ZTR variando de acordo com as unidades estratigráficas, estas sugerem fontes ígneas, metamórficas e sedimentares oriundas do Cráton Amazônico, Cinturão Araguaia, Bacia do Grajaú ou Sub-Bacia de Cametá.

A relação lateral entre as formações Ipixuna, Barreiras e Pós-Barreiras/Argila de Belterra ao longo da área de estudo deu-se provavelmente por sedimentação em "on lap" decorrente de geração de espaço acomodacional por abatimento de blocos da Formação Ipixuna.

\section{AGRADECIMENTOS}

Expressamos nossos agradecimentos à Universidade Federal do Sul e Sudeste do Pará (UNIFESSPA) pela infraestrutura física que possibilitou a execução desta pesquisa e à Universidade Federal do Pará (UFPA) pela confecção das lâminas. Agradecemos aos colegas Marcos Thiago, Kelly Caldas, aos Professores Aderson David de Lima e Ana Valéria Pinheiro da Faculdade de Geologia (FAGEO) pelas contribuições. Por fim, agradecemos também aos avaliadores anônimos da revista, cujas sugestões e correções contribuíram para melhorar a versão final do artigo. 


\section{REFERÊNCIAS}

ARAI, M.; UESUGUI, N.; ROSSETTI, D.D.F.; GÓES, A.M. Considerações sobre a idade do Grupo Barreiras no nordeste do Estado do Pará. In CONGRESSO BRASILEIRO DE GEOLOGIA, 1988, Belém. Anais... Belém: SBG, v. 35, p. 738-752.

ARAI, M. A Grande Elevação Eustática do Mioceno e Sua Influência na Origem do Grupo Barreiras, São Paulo. Revista do Instituto de Geociências USP, v. 6, n. 2, p. 1-6, 2006.

ARAÚJO, V.D.; REYES-PERES, Y.A.; OLIVEIRA LIMA, R.; PELOSI, A.P.D.M.R.; MENEZES, L.; CÓRDOBA, V.C.; LIMA-FILHO, F.P. Fácies e Sistema Deposicional da Formação Barreiras na Região da Barreira do Inferno, Litoral Oriental do Rio Grande do Norte, São Paulo. Revista do Instituto de Geociências USP, v.6, n. 2, p. 43-49, 2006.

AZEVEDO, R.P. Tectonic Evolution of Brazilian Equatorial Continental Margin Basin: London, 1991, 412p. PhD thesis, Royal School of Mines Imperial College.

AVENIUS, C.G. Cronostratigraphic study of the Post-rift/Sinrift unconformity, Marajó rift system, Brazil. Belém: TEBCO, p. 98, 1988.

CARNEIRO, C.D.R.; ALMEIDA, F.F.M.; HASUI, Y.; ZALÁN, P.V.; TEIXEIRA, J.B.G. Estágios evolutivos do Brasil no Fanerozoico. In: HASUI, Y., CARNEIRO, C.D.R., ALMEIDA, F.F.M.A., BARTORELLI, A. (org.) Geologia do Brasil. São Paulo, Beca. 2012. v. 1, n. 6, p. 131-136, 2012.

COSTA, J.B.S; HASUI, Y.; BEMERGUY, R.L.; SOARESJÚNIOR, A.V.; VILLEGAS, J. Tectonics and paleogeography of the Marajó Basin, northern Brazil. Anais da Academia Brasileira de Ciências, v. 74, n. 3, p. 519-53, 2002.

COSTA, J.B.S.; BEMERGUY, R.L.; HASUI, Y.; BORGES, M.S.; FERREIRA JR., C.R.P.; BEZERRA, P.E.L.; COSTA, M.L.; FERNANDES, J.M.G. Neotectônica da região amazônica: aspectos tectônicos, geomorfológicos e deposicionais. Belo Horizonte. Geonomos, v. 44, p. 23-44, 1996.

COUTINHO, J.M.V.; COIMBRA, A.M. Tabela de identificação Óptica de Minerais Transparentes em Sedimentos. Curitiba/São Paulo, UFPR/USP. 17p., 2005.

FELIPE, L.B. Geologia, Geomorfologia e Morfotectônica da Região de Marabá - PA. Rio Claro, 2012. Tese (Doutorado em Geologia Regional), Universidade Estadual Paulista Júlio de Mesquita Filho.

FURRIER, M.; ARAÚJO, M.E.; MENESES, L.F. Geomorfologia e Tectônica da Formação Barreiras no Estado da Paraíba, São Paulo. Revista do Instituto de Geociências USP, v. 6, n. 2, p. 61-70, 2006.

GALEHOUSE, J.S. Point counting. In CARVER, R. E. (ed.) Procedures in Sedimentary Petrology. Wiley Interscience, New York, p. 385-408, 1971.

GALVÃO, M.V.G. Evolução Termodinâmica da Bacia do Marajó, Estado do Pará, Brasil. Ouro Preto, 1991, 193p. Dissertação (Mestrado), Universidade de Ouro Preto,

GÓES A.M. Estudo sedimentológico dos sedimentos Barreiras, Ipixuna e Itapecuru, no nordeste do Estado do Pará e noroeste do Maranhão. Belém, 1981. 55p. Dissertação (Mestrado em Ciências, na área de Geologia), Universidade Federal do Pará.

HARWOOD, G. Microscopic techniques. II. Principles of sedimentary petrography. In: TUCKER, M.E. (ed.) Techniques in Sedimentology, Blackwell, Oxford, p. 108$173,1988$.

HUBERT, J.F. A zircon-tourmaline-rutile maturity index and the interdependence of the composition of heavy mineral assemblages with the gross composition and texture of sandstones. Journal of Sedimentary Research, 32(3), 1962.

KOTSCHOUBEY, B. \& TRUCKENBRODT, W. Evolução poligenética das bauxitas do distrito de ParagominasAçailândia, Estados do Pará e Maranhão. Brazilian Journal of Geology, v.. 11, n. 3, p. 193-202, 1981.

KOTSCHOUBEY, B.; TRUCKENBRODT, W. Evidencias de bauxitização tardia no nordeste do estado do Pará. In: SIMPÓSIO DE GEOLOGIA DA AMAZÔNIA, 4, 1994. Anais...SBG/Norte, p. 269-271.

KOTSCHOUBEY, B.; TRUCKENBRODT, W.; CALAF, J.M. C. Evolução geológica da porção meridional da Província Bauxitífera de Paragominas durante o Neógeno/Pleistoceno (Noroeste da Bacia do Grajaú, Nordeste do Pará e extremo oeste d Maranhão). Revista Brasileira de Geociências, v. 35, n. 2, p. 263-272, 2005.

KOTSCHOUBEY, B.; TRUCKENBRODT, W.; HIERONYMUS, B. Phases and zonality of the bauxitic alteration in the northeast of the State of Para (Brazil). Traveaux ICSOBA, p. 16-17, 1987.

KOTSCHOUBEY, B.; TRUCKENBRODT, W.; HIERONYMUS, B. Bauxite deposits of Paragominas. In: CARVALHO, A.; BOULANGÉ, B.; MELFI, A.J.; LUCAS, Y. (eds.) Brasiliam Bauxites. USP, FADESP, ORSTOM, p. 75-106, 1997.

LIMA, H.P. Notas sobre a análise estratigráfica da Bacia de Marajó. Belém: Petrobrás, 34p., 1987

LIMA, C.C.U.; BOAS, G.D.S.V.; BEZERRA, F.H.R. Faciologia e análise tectônica preliminar da Formação Barreiras no Litoral Sul do estado da Bahia, São Paulo. Revista do Instituto de Geociências USP, v. 6, n. 2, p. 71-80, 2006

LIMA, M. R.; FULFARO, V. J.; BARTORELLI, A. Análise palinológica de sedimentos cretáceos da região de Marabá, estado do Pará. Paleobotânica e Áreas Afins na América do Sul - Boletim do Instituto de Geociências, USP 11: 155161, 1980.

MACAMBIRA, E.M.B. \& RICCI, P.S. Geologia e recursos minerais da Folha Tucuruí - SA.22-Z-C, Estado do Pará. Escala 1:250.00. Programa Geologia do Brasil (PGB) Integração, Atualização e Difusão de Dados da Geologia do Brasil. Belém: CPRM, 2014. 122p.

MANGE, M.A. \& MAURER, H.F.W. Heavy Minerals in Colour. London, UK: Chapman \& Hall, p. 1-154, 1992.

MELO, W.F. Análise de Fácies da Formação Ipixuna, SubBacia de Mocajuba, Sul do Sistema de Gráben do Marajó, Região Entre os Municípios de Nova Ipixuna e Jacundá. Marabá, 2013, 51p. Trabalho de Conclusão de Curso (Graduação em Geologia), Universidade Federal do Pará - UFPA.

MORTON, A. Value of Heavy Minerals in Sediments and Sedimentary Rocks for Provenance, Transport History and Stratigraphic Correlation. In: SYLVESTER, P. (Ed.), Quantitative mineralogy and microanalysis of sediments and sedimentary rocks. Mineral. Soc. Canada Short Course, v. 42, p. 133-165, St. John's NL., 2012.

MORTON, A.C. \& HALLSWORTH, C.R. Processes controlling the composition of heavy mineral assemblages in sandstones. Sedimentary Geology, v. 124, p. 3-29, 1998.

NASCIMENTO, M.S. Distribuição Estratigráfica e Proveniência de Minerais Pesados das Formações Ipixuna e Barreiras, Região do Rio Capim, Sul da Sub-Bacia de Cametá. Revista Brasileira de Geociências, v. 35, p. 49-58, 2005.

NASCIMENTO, M.S. \& GÓES, A.M. Petrografia de arenitos e minerais pesados de depósitos cretáceos (Grupo Itapecuru), Bacia de São Luís-Grajaú, norte do Brasil. Revista Brasileira de Geociências, v. 37, n. 1, p. 50-63, 2007.

NESSE, W.D. Introduction to optical mineralogy. Third edition. New York: Oxford University Press, 2004.

OLIVEIRA, J.G.F. \& SILVA, R.C.S. Geologia e recursos minerais da folha Belém SA. 22-X D-III, Estado do Pará, Escala: 1:100.000. Belém: CPRM 2011. 91p.

PETTIJOHN, F.J.; POTTER, P.E.; SIECER, R. Sand and sandstone. New York, Heidelberg, Berlin, Springer-Verlag. p. 1-618, 1973. 
POWERS, M.C.A. A new roundness scale for sedimentary particles. Journal of Sedimentary Petrology, v. 23, p 117119, 1953.

ROSSETTI, D.F. Paleosurfaces from northeastern Amazônia as a key for reconstructing paleolandscapes and understanding weathering products. Sedimentary Geology, v. 169, p. 151174, 2004.

ROSSETTI, D.F.; GÓES, A.M.; TRUCKENBRODT, W. A Influência Marinha nos sedimentos Barreiras. Boletim do Museu Paraense Emílio Goeld, 1990.

ROSSETTI, D.F.; ROCCA R.R.; TATUMI, S.H. Evolução dos Sedimentos Pós-Barreiras na zona costeira da Bacia São Luís, Maranhão, Brasil. Boletim do Museu Paraense Emílio Goeldi. Ciências Naturais, v. 8, n. 1, p. 11-25, 2013.

ROSSETTI, D.F. \& SANTOS JR., A.E.S. Facies architecture in a tectonically influenced stuarine incised valley fill of Miocene age, northern Brazil. Journal of South American Earth Sciences, v. 17, p. 267-284, 2004.

ROSSETTI, D.F.; TRUCKENBRODT, W.; GÓES, A.M. Estudo Paleoambiental e Estratigráfico dos Sedimentos Barreiras e Pós-Barreiras na Região Bragantina, Nordeste do Pará. Boletim do Museu Paraense Emílio Goeldi, Série Ciências da Terra, 1989.

SANTOS JR., A.E.A.; ROSSETTI, D.F. Paleoambiente e estratigrafia da Formação Ipixuna, Área do Rio Capim, Leste da Bacia de Cametá. Revista Brasileira de Geociências, v. 33, n.3, p. 313-324, 2003.

SANTOS JR., A.E.A. \& ROSSETTI, D.F. Depositional Model of the Ipixuna Formation (Late Cretaceus?-Early Tertary), Rio Capim area, northern Brazil. Latin American Journal of Sedimentology and Basin Analysis, v. 13, n. 2, p. 65-87, 2006.

SANTOS JR., A.E.A. Análise integrada dos depósitos de caulim na região do Rio Capim: fácies, estratigrafia, petrografia e isótopos estáveis. Belém, 2006. 116 p. Tese (Doutorado em Geologia), Centro de Geociências, Universidade Federal do Pará.

SANTOS JR. A.E.A. Reconstrução paleoambiental e estratigráfica de depósitos cretáceos e terciários expostos na borda sudeste da Sub-Bacia de Cametá, norte do Brasil. Belém, 2002. 131p. Dissertação (Mestrado em Geologia), Centro de Geociências, Universidade Federal do Pará.

SILVA, A.J.C.L.P., LOPES, R.C., VASCONCELOS, A.M., BAHIA, R.B.C. (2003). Bacias Sedimentares Paleozoicas e Meso-Cenozoicas Interiores. In: BIZZI, L.A.; SCHOBBENHAUS, C.; VIDOTTI, R.M.; GONÇALVES J.H. (Eds.). Geologia, Tectônica e Recursos Minerais do Brasil, v. 1, p. 55-85). Brasília: CPRM.

SOARES JÚNIOR, A.V. A Fragmentação do Gondwana na Região Meio-Norte do Brasil durante o Mesozoico. Belém, 2007. 193p. Tese (Doutorado)-Instituto de Geociências, Universidade Federal do Pará.
SOARES JUNIOR, A.V.; HASUI, Y.; BEMERGUY, R.L. O Rio Amazonas. In: HASUI, Y.; DAL RÉ CARNEIRO, C.; ALMEIDA, F.F.M; BARTORELLI, A. (Org.). Geologia do Brasil. 1ed. São Paulo: Beca, 2012, v. 1, p. 611-622.

SOARES JR, A.V.; HASUI, Y.; COSTA, J.B.S.; MACHADO, F.B. Evolução do rifteamento e Paleogeografia da Margem Atlântica Equatorial do Brasil: Triássico ao Holoceno. Geociências, v. 30, p. 370 - 390, 2011.

SOARES JR. A.V.; COSTA, J.B.; HASUI, Y. Evolução da Margem Atlântica Equatorial do Brasil: Três fases distensivas, São Paulo, UNESP, Geociências, v. 27, n. 4, p. 427-437, 2008.

SOUZA, S.C.R. Fácies e Estratigrafia da Sedimentação Proximal da Formação Barreiras, Sub-Bacia de Mocajuba, Extremo Sul do Sistema de Gráben do Marajó, Região de Marabá. Marabá, 2012. 46p. Trabalho de Conclusão de Curso (Graduação em Geologia), Faculdade de Geologia, Universidade Federal do Pará.

SOUZA, S.C.R. \& SANTOS, JR. A.E.A. Fácies e estratigrafia da sedimentação proximal da Formação Barreiras, sul do Sistema de Grabén do Marajó, região de Marabá. In: CONGRESSO BRASILEIRO DE GEOLOGIA, 45, 2010, Belém. Anais... Belém: SBG, 2010.

TRUCKENBRODT, W. \& KOTSCHOUBEY, B. Argila de Belterra-cobertura terciária das bauxitas amazônicas. Revista Brasileira de Geociências, São Paulo, v. 11, n. 3, p. 203-208, 1981.

TOMITA, T. Geologic significance of the color of granite zircon, and the discovery of the Pre-Cambrian in Japan. Memoirs of the Faculty of Science, Kyushu University, Series D. Earth and Planetary Sciences, v. 4, n. 2, p. 135-161, 1954.

VASQUEZ, M.L. \& ROSA-COSTA, L.T. (Organizadores) Geologia e Recursos Minerais do Estado do Pará: Sistema de Informações Geográficas - SIG: texto explicativo dos mapas Geológico e Tectônico e de Recursos Minerais do Estado do Pará. Escala 1:1.000.000, 329p. CPRM, Belém, 2008.

VILLEGAS, J.M.C. Geologia estrutural da Bacia do Marajó. Belém, 1994. 120p. Dissertação (Mestrado em Geologia), Centro de Geociências, Universidade Federal do Pará.

ZALÁN, P.V.; MATSUDA, N.S. Bacia do Marajó. Boletim de Geociências. Petrobras, Rio de Janeiro, v. 15, n. 2, p. 311319, 2007. 